\title{
High and New Technology Enterprise Introducing High-level Overseas Talents Policy Effectiveness Research
}

\author{
Yongming Pan ${ }^{\mathrm{a}}$ and Jiayu $\mathrm{Xi}^{\mathrm{b}, *}$ \\ School of Tianjin University of Technology, Tianjin 300384, China; \\ a609574311@qq.com, b450103216@qq.com \\ Corresponding author: Jiayu Xi
}

Keywords: Human Resources, Policy Effectiveness, Evaluation Analysis, Talent Introduce, Talent Utilization.

\begin{abstract}
After successfully being certificated as a free trade area in Tianjin, a series of preferential tax policy and other policies have been put forward to attract domestic and foreign enterprises in Binhai New Area, especially to attract the large number of outstanding enterprises take root in Binhai, Tianjin. One of the most impressive target companies is the high and new technology enterprise, they will lag behind the "made in China" become a cheery "wisdom in China". A policy for high and new technology enterprise to attract high-level overseas talents efficiently brought the overseas high-level talents to Tianjin. The thesis makes a discussion on the influence of the policy according to the analysis of the situation of the introducing and employing overseas people with high capability. With a comparative study of the standard evaluating and introducing the overseas people with high capability, the thesis puts forward some understandings and suggestion to fulfill the guidance function of policy and how to introducing and employing overseas people with high capability.
\end{abstract}

\section{Introduction}

After the successful qualification for a free trade area of Tianjin, the Binhai New Area is now putting forward a series of preferential tax and other policies to attract domestic and foreign enterprises, and there is a large number of outstanding enterprises take root in Binhai, set in Tianjin. One of the most impressive companies is the high and new technology enterprise, they will lag behind the "made in China" become a cheery "wisdom in China". A high and new technology enterprise's successful introduction of high-level overseas talents policy efficiently brought the overseas high-level talents to Tianjin. Various regions in the introduction and use of high-level overseas talents, both of the purpose and the direction are clear. With the features of local high-quality projects, the eastern coastal area and central city attracted many overseas high-level talents to return home.

All localities and departments attach great importance to the introduction of overseas talent, such as table 1:

Table 1. Regional introduction of overseas talent work summary table accordingly

\begin{tabular}{|c|c|}
\hline Region & \begin{tabular}{c} 
Overseas talent introduction \\
\hline Jiangsu
\end{tabular} \\
\hline Wuxi & $\begin{array}{r}\text { The implementation of high level innovation and Entrepreneurship } \\
\text { Talent introduction program" }\end{array}$ \\
\hline Beijing & $\begin{array}{c}\text { Formulated a number of provisions to encourage overseas students to work in } \\
\text { Beijing and the opinions on further encouraging overseas high-level talents to } \\
\text { work in Beijing, etc. }\end{array}$ \\
\hline Shanghai & $\begin{array}{r}\text { Formulated to encourage students to work in Shanghai and } \\
\text { Certain provisions of entrepreneurship }\end{array}$ \\
\hline Guangxi & Implementation of innovation and Entrepreneurship Talent Highland program \\
\hline
\end{tabular}




\section{Research Significance}

\subsection{Theoretical Basis.}

Talent is the source of rejuvenation. Since the beginning of the new century, the comprehensive national power has been transformed into the competition of science, technology and economy. This makes the sign of the advanced productive forces of the high-tech industry has come into the light. In foreign countries, individuals, organizations, social and regional differences are the four main research directions of talent flow theory, and the studies of talent introduction theory include human capital theory, polarization -- trickledown effect theory, Preiss model, the Cook curve theory, and the participants decided to "model and Alderfer's ERG theory.

In fact, there are many experts and scholars on the introduction and use of talent, and put forward some theories and evaluation methods. Including the cost benefit analysis of the government behavior model theory, the flow of talent in theory, joint decision model theory, theory of relativity theory and the effect of flow model "of overseas talents backflow".

\subsection{Status Analysis.}

The term "high and new technology" was proposed in 1970s and was widely used in the 80s, but there is not a consistent, rigorous, and standard definition of the new and high technology. Taking into account the different national conditions, the definition of the concept of the best and the object of study of the state line, because the study is in China's high-tech enterprises overseas high-level talents as the research object, this paper adopts the provisions of China's high-tech. High and new technology enterprises have the characteristics of high innovation, high risk, high investment, high yield and high permeability.

Table 2. SWOT analysis on a high and new technology enterprise

\begin{tabular}{|c|c|}
\hline Strength & Weakness \\
Promote the transformation of enterprise into science & Single industrial structure \\
and technology & Over reliance on Innovation \\
Enhance corporate brand image & Domestic technology behind \\
Enjoy preferential tax policies & Management needs to be strengthened \\
Improve enterprise market value & Talent introduction difficulty \\
Improve enterprise capital value & threat \\
\hline Opportunity & Fierce competition in the same industry \\
National and local policy support & High input, high risk \\
High yield & ing
\end{tabular}

The talent structure of high-tech enterprises mainly includes basic talents, middle and senior talents and advanced talents. Overseas high-level talents because of their educational background and work experience, such as the accumulation of reserves, it is easy to become the strategic decision of the cutting-edge talent. However, there are many obstacles to the introduction and use of the talents, and the government's policies have helped to provide a platform for them. In the introduction of the Interim Measures for the introduction of high-level overseas talent, according to the official announcement in 2008 alone, that there are 2000 overseas high-level talents are attracted, and there are various high-tech enterprises attracted throughout the country.

The government's policy bias to the introduction of new high-tech enterprises overseas talents to bring the gospel. More than 70 companies interested in entrepreneurial talent founded in Tianjin, with a total registered capital of 700 million yuan, whose turnover of more than 4 billion yuan, the profit of 600 million yuan, tax of nearly 200 million yuan, supporting the development of Tianjin with their contribution.

\subsection{Existing Problems.}

According to the study of high tech enterprises in the aspect of introduction and use of overseas high-level talents, there are some significant findings as well as some deficiencies:

Firstly, the way to attract talent, the introduction of the channel is not wide enough and the introduction of high-level overseas talents cannot meet the needs of the development of high-tech enterprises. Secondly, the existence of blind introduction cannot be ignored. The quality of talent in 
many cases is not put in the primary consideration. Thirdly, it is the service after introduction cannot follow up for those who failed to get into digital management system, and the lack of service level is the also the problem where the attention should be paid. Last but not least, to encourage the return policy, incentive mechanism and the security system are still not perfect, the platform is not big enough for talents to show their talence.

\section{Policy Effectiveness Evaluation}

Policy effectiveness means the implementation of the policy implementation agencies and personnel to achieve the policy objectives. In the implementation of the policy process, it is the ability to swing their own policies and to achieve the optimal allocation of resources. The introduction and use of high-level overseas talents evaluation standard should be adjusted with the consideration that whether it brought the advanced concept of social development, whether it brings the advanced science and technology, whether it can be helpful in carrying out more cooperation platform and whether it brings more lucrative profits in overseas markets.

Thus, the establishment of social benefit orientation model, the evaluation of the social impact and economic benefits of the use of overseas high-level innovative talents is kind of important.

$$
\begin{aligned}
& \mathrm{S}_{\mathrm{t}+1}=1-\mathrm{dS}_{\mathrm{t}}{ }^{2}+\mathrm{eP}_{\mathrm{t}} \\
& \mathrm{P}_{\mathrm{t}+1}=\mathrm{fP}_{\mathrm{t}}
\end{aligned}
$$

Which:

$\mathrm{S}_{\mathrm{t}}$ : social performance of $\mathrm{t}$

$\mathrm{S}_{\mathrm{t}+1}$ : social performance of $\mathrm{t}+1$

$\mathrm{P}_{\mathrm{t}}$ : the economic benefits of $\mathrm{t}$

$\mathrm{P}_{\mathrm{t}+1}$ : the economic benefits of $\mathrm{t}+1$

$S_{0:}$ the initial value of social performance ( $t=m$ value of a fixed value of $\left.S_{t}\right)$

$\mathrm{P}_{0}$ : the initial value of economic benefits $(\mathrm{t}=\mathrm{m}$ value of a fixed value of $\mathrm{Pt})$

$\mathrm{D}$ : the impact of talent introduction on social performance

F: the influence of talent introduction on economic profit

E: social economic correlation coefficient

For this dynamic model, we first make some restrictions:

A, coefficient $\mathrm{f}$ is a fixed value, e (Social Economic Association) $=1.0$;

$\mathrm{B}$, social performance level must be positive.

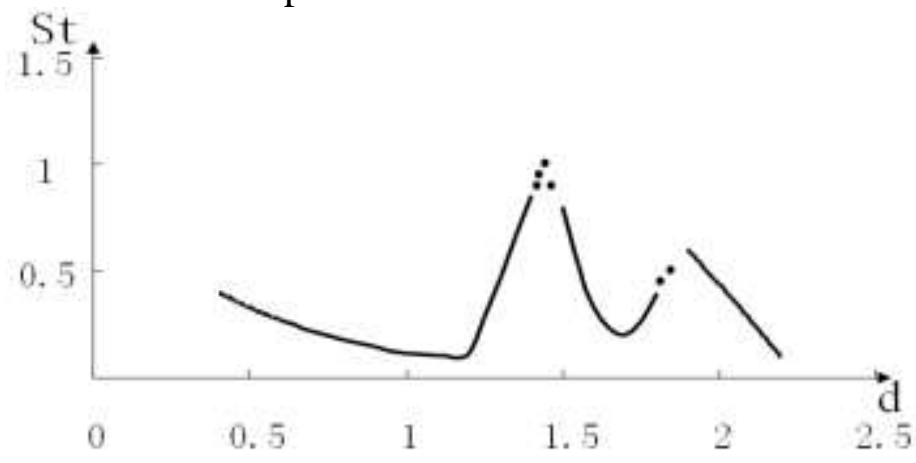

Fig. 1 Target social performance variation

The vertical axis represents the social performance of $S_{t}$ (social performance $>0$ ), the horizontal axis represents the introduction of overseas high-level talents of social performance influence coefficient $\mathrm{d}$, build a Cartesian coordinate system, through translation finishing, that two target social performance changes. As figure 1:

As a matter of fact, the figure will change because of the difference of coefficient $f$. But we can still see from the figure that the influence of coefficient in the introduction of high-level overseas talents to the economic benefits of $\mathrm{f}$ and $\mathrm{e}$ (Social-Economic correlation coefficient) under certain circumstances. Different coefficient of $d$ will cause the sudden change of social performance. This mutation will bring many unexpected problems. Therefore, in order to obtain a stable and optimized 
society, the economic performance of two variables, under certain economic background and the social relations of production, it is necessary to select the coefficient $d$ carefully.

\section{Summary}

In the country, to carry out the introduction of overseas high-level talents in the environment, the high-tech enterprises have also put forward a series of related policies, and achieved some results. This paper introduced the status and Performance Research on high-tech enterprises overseas high-level talents shortage, drew the following conclusion: the introduction of foreign high-level personnel work is not only conducive to the development of high-tech enterprises, both in the social and economic development aspects. We must keep it in the long term, thinking from the perspective of strategy. For high-level personnel selection, it must be selected seriously, and we need to carefully organize the introduction of planning needs of overseas high-level talents to provide a good platform to establish related personnel completed and feasible policy. Perfecting the talent evaluation system. In short, we aim to enhance the core competitiveness of enterprises through the introduction of high-level overseas talent, and make the development of social economy to match the height.

Tianjin Bohai Sea Economic Zone as a pearl on the double effect from Liaoning, in the high-tech enterprises like Siasun's economic and social development of the province. The Binhai New Area, as the second batch of economic free trade zone on the richly endowed by nature policy advantage, geographical advantage, economic advantage, understand the high level overseas the introduction of talent and the importance of the work, adhere to standards. To standardize the procedures, it plans to introduce overseas high-level talents through detailed arrangement and organization system, combine with Tianjin itself advantage, put forward to adapt with the local characteristics of Tianjin preferential policies to attract high-tech enterprises more rooted in the construction of Tianjin Binhai.

To sum up, a large scale, the strength of the innovative talent team is conducive to enterprise development, to help enterprises achieve their strategic objectives of the division. While overseas high-level talents not only have advanced knowledge structure, but also grasp the world first-class technology, thus they are skilled in the use of advanced technology and have a winning point of high-end industry. The introduction of high-level talents demand directly from abroad is the fastest way to help companies integrate personnel, and it is also a powerful measure to further deepen reform and opening up. Enhancing the comprehensive strength that is an outstanding work to achieve the enterprise talent. And when it comes to the construction of innovative enterprises, primary task is to help the high-tech enterprises form the strategic target and use research on introduction of overseas high-level talents. Promoting high-tech enterprises and the enhancement of social economy would have a far-reaching influence.

\section{References}

[1] Hao Xuan. Study on the impact of financial institutions' unconventional business development on the effectiveness of financial regulation and control policy.Western Finance. Vol. 2015 No. 04, p. 51-56.

[2] Li Xiyuan, Bian Shuangying, Zhang Wenjuan, et al. Evaluation of the effectiveness of high-level talents policy: a case study of East Lake New Technology Industrial Development Zone. Science and Technology Progress and Countermeasures.Vol. 2014 No. 21, p. 114-119.

[3] Wang Liqing, Feng Yang, et al. The retardation factor and efficiency improvement of public policy implementation. People's Forum. Vol. 2014 No. 14, p. 42-44.

[4] Liu Jiashun, Zhang Zhen, et al. Study on the effectiveness of the implementation of talent policy. Contemporary Economy.Vol. 2014 No. 03 ,p.123-125.

[5] Information on:www.tj.gov.cn 